\title{
CACNA1A-p.Thr501Met mutation associated with familial hemiplegic migraine: a family report
}

\author{
Marina Romozzi ${ }^{1,2}$, Guido Primiano ${ }^{1,3}$, Eleonora Rollo ${ }^{1,2}$, Lorena Travaglini ${ }^{4}$, Paolo Calabresi ${ }^{1,2}$, \\ Serenella Servidei ${ }^{1,3}$ and Catello Vollono ${ }^{1,3^{*}}$ (iD
}

\begin{abstract}
Background and aims: Hemiplegic migraine $(H M)$ is a rare form of migraine characterized by the presence of a motor and other types of aura. HM can be sporadic or familial. Familial hemiplegic migraine (FHM) is an autosomal dominant disorder, classified into 3 subtypes, based on the gene involved (CACNA1A in FHM1, ATP1A2 in FHM2 and SCN1A in FHM3). The clinical presentation is highly heterogeneous and some attacks may be severe.

We report the clinical characteristics and genetic analysis of 12 patients belonging to a family with CACNA1Ap.Thr501Met gene mutation.
\end{abstract}

Methods: We screened for mutations in CACNA1A gene 15 patients belonging to the same family. The exonic sequences of CACNA1A were analyzed using a Tru-seq ${ }^{\circledR}$ Custom Amplicon (TSCA) (Illumina Inc., San Diego, CA) targeted capture and paired end library kit. Sanger sequencing was used to confirm CACNA1A variants and segregation analysis.

Results: CACNA1A-p.Thr501Met mutation was found in 12 of the 15 patients screened, which was compatible with the diagnosis of FHM1.

Attacks of hemiplegic migraine were reported by 10 of the 12 subjects (83.33\%). Only one subject developed persistent mild cerebellar symptoms and none of the subjects developed cerebellar atrophy.

Discussion: The variant p.Thr501Met was described previously in association with episodic ataxia and rarely with FHM related to cerebellar symptoms. FHM1 has a broad clinical spectrum and about half of the families have cerebellar involvement. In our study, only one patient developed persistent cerebellar deficits. These data suggest that CACNA1A-p.Thr501Met mutation can occur prevalently as hemiplegic migraine.

Keywords: Hemiplegic migraine, CACNA1A-p.Thr501Met mutation, Cortical spreading depression, Episodic ataxia, Cerebellar atrophy

\footnotetext{
* Correspondence: Ivol@libero.it

'Dipartimento Universitario di Neuroscienze, Università Cattolica del Sacro Cuore, Rome, Italy

${ }^{3}$ Dipartimento di Scienze dell'invecchiamento, Neurofisiopatologia, Neurologiche, Ortopediche e della Testa-Collo, Fondazione Policlinico Universitario Agostino Gemelli IRCCS, Largo Agostino Gemelli nº -, 00168 Rome, Italy

Full list of author information is available at the end of the article
}

(c) The Author(s). 2021 Open Access This article is licensed under a Creative Commons Attribution 4.0 International License, which permits use, sharing, adaptation, distribution and reproduction in any medium or format, as long as you give appropriate credit to the original author(s) and the source, provide a link to the Creative Commons licence, and indicate if changes were made. The images or other third party material in this article are included in the article's Creative Commons licence, unless indicated otherwise in a credit line to the material. If material is not included in the article's Creative Commons licence and your intended use is not permitted by statutory regulation or exceeds the permitted use, you will need to obtain permission directly from the copyright holder. To view a copy of this licence, visit http://creativecommons.org/licenses/by/4.0/. The Creative Commons Public Domain Dedication waiver (http://creativecommons.org/publicdomain/zero/1.0/) applies to the data made available in this article, unless otherwise stated in a credit line to the data. 


\section{Introduction}

Hemiplegic migraine (HM) is a rare form of migraine characterized by the presence of a motor aura and other types of aura. HM can occur as a sporadic or familial disorder. Familial hemiplegic migraine (FHM) is an autosomal dominant disease with reduced penetrance and variable expressivity. According to the International Classification of Headache Disorders-3 (ICHD-3), the disease is classified into 3 subtypes, based on the gene involved. Mutations in the CACNA1A gene, which encodes the alpha-1A subunit of the P/Q type calcium channel, cause FHM1 [1]. In addition to FHM1, CACN $A 1 A$ gene mutations have been associated with episodic ataxia type 2 and spinocerebellar ataxia type $6[2,3]$. Mutations in the ATP1A2 gene, which encodes a catalytic subunit of a sodium/potassium ATPase, cause FHM2. FHM3 is caused by mutations in the SCN1A gene that encodes the alpha subunit of the neuronal voltage-gated sodium channel [1]. Recently, a fourth gene, PRRT2, which encodes a proline-rich transmembrane protein, has been associated with FHM4 [4]. Therefore, it is likely that the established mutations account for a small percentage of cases of FHM and other not yet identified genes are involved [4].

The clinical presentation of the various forms of FHM is highly variable. Severe attacks can be accompanied by seizures, coma, encephalopathy, fever, cerebellar involvement, cerebral edema or cerebral infarction [5].

The pathophysiological mechanism underlying the motor aura is probably cortical spreading depression (CSD). Mutations related to HM increase neuronal excitability, leading to a higher susceptibility to CSD [6].

Initial therapy with verapamil, flunarizine or acetazolamide is recommended for patients with HM as a preventive treatment. In patients who have persistent aura symptoms that predominate over headache, lamotrigine represents another therapeutic option [5].

About half of the families with FHM1 have cerebellar involvement, including ataxia, gaze-evoked nystagmus, and vermian atrophy [7].

The p.Thr501Met variant was previously described only in episodic ataxia [8] or rarely in HM strictly associated with cerebellar symptoms [9].

We report the clinical characteristics and genetic analysis of 12 patients belonging to a large family with CACNA1A-p.Thr501Met gene mutation and a prevalent hemiplegic phenotype.

\section{Methods}

Upon informed consent, we screened for mutations in $C A C N A 1 A$ gene 15 subjects (including unaffected relatives) belonging to the family from 3 successive generations (Fig. 1). The exonic sequences of CACNA1A were analyzed using a Tru-seq ${ }^{\ominus}$ Custom Amplicon (TSCA) (Illumina Inc., San Diego, CA) targeted capture and paired end library kit. Variants were detected by means of the HaplotypeCaller software package of the Genome Analysis Toolkit (GATK) suite and filtered so that to include only variants covered by at least 20 reads. Highquality variants were annotated and considered when not reported or having a low allele frequency $<0.005$ in genome $\mathrm{AD}$ exomes database and occurring with a frequency $<0.01$ in our in-house database. Sanger sequencing was used to confirm CACNA1A variants and segregation analysis.

\section{Case presentation}

The index patient (Table 1, I-5) is a 71-year-old man who was admitted to our Institute for an episode of migraine associated with fever, right hemiparesis, aphasia

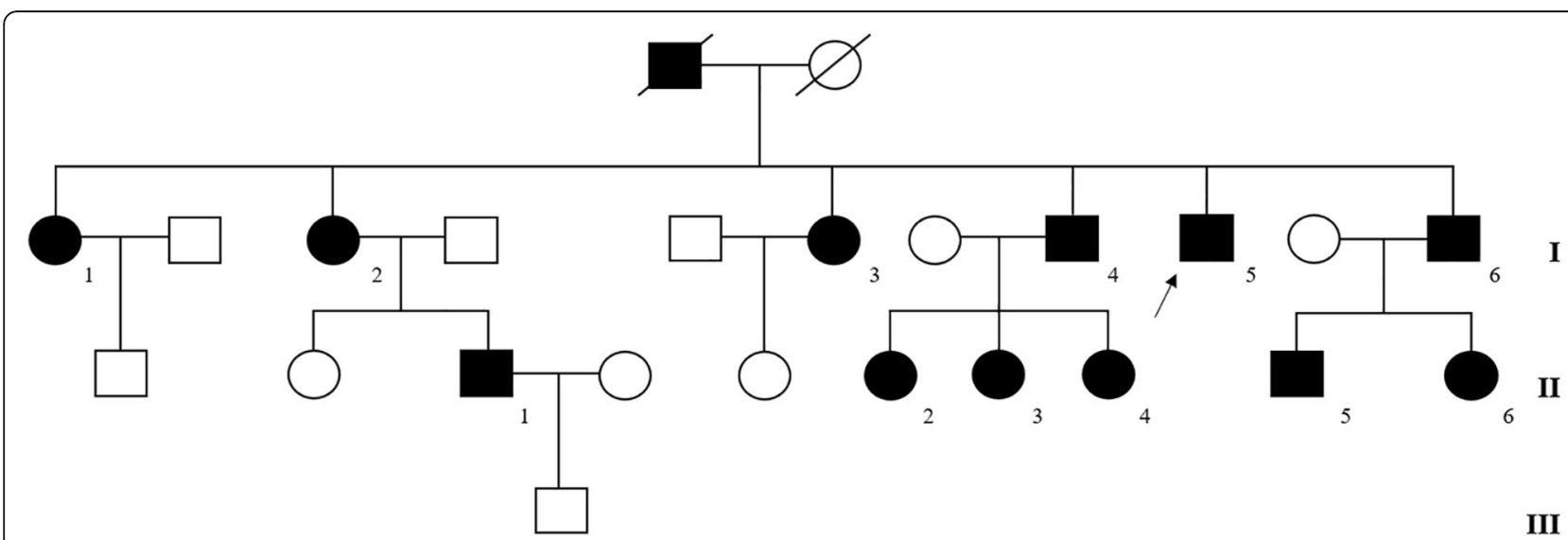

Fig. 1 FHM1 pedigree chart of the family. Circles represent the females and squares represent males. Black squares and circles indicate affected males and females, respectively. White squares or circles represent members without FHM. The diagonal lines represent deceased subjects. The arrow indicates the index patient 
Table 1 Demographic, clinical characteristics and current prophylactic treatment of the 12 patients with the CACNA1A-p.Thr501Met mutation

\begin{tabular}{|c|c|c|c|c|c|c|c|c|c|}
\hline & Sex & $\begin{array}{l}\text { Headache types } \\
\text { IHS criteria }\end{array}$ & Age & $\begin{array}{l}\text { Age of onset } \\
\text { (years) }\end{array}$ & $\begin{array}{l}\text { Attacks per } \\
\text { month }\end{array}$ & $\begin{array}{l}\text { Duration } \\
\text { (hours) }\end{array}$ & Triggers & Comorbidities & $\begin{array}{l}\text { Prophylactic } \\
\text { Treatment }\end{array}$ \\
\hline I-1 & $\mathrm{F}$ & $\mathrm{HM}$ & 76 & 24 & 3 & $0,5-4$ & Stress & breast cancer, DM 2 & - \\
\hline $1-2$ & $\mathrm{~F}$ & $\mathrm{HM}$ & 63 & 18 & 2 & $3-700$ & Pregnancy & DM 2, AH, panic disorder & - \\
\hline $1-3$ & $\mathrm{~F}$ & HM & 75 & 15 & 3 & $0,5-168$ & Menstruations & major depressive disorder, DM 2 & Amitriptyline \\
\hline I-4 & M & $\mathrm{HM}$ & 68 & 12 & 1 & $4-96$ & Mild head trauma & $\mathrm{AH}, \mathrm{DM} 2$ & - \\
\hline $1-5$ & M & $\mathrm{HM}$ & 71 & 6 & 0 & $3-168$ & Stress, bright ligths & $\mathrm{AH}, \mathrm{DM} 2, \mathrm{COPD}$ & $\begin{array}{l}\text { Acetazolamide + } \\
\text { Lamotrigine }\end{array}$ \\
\hline $1-6$ & M & $\mathrm{HM}$ & 66 & 6 & 2 & $3-168$ & - & DM 2, hepatitis B, hiatal hernia & Lamotrigine \\
\hline$\| 1-1$ & M & ETTH & 45 & 15 & 0 & $1-48$ & - & - & - \\
\hline II-2 & $F$ & $\mathrm{MO}$ & 29 & 20 & 1 & $0,5-6$ & Stress, sleep & - & - \\
\hline II-3 & $\mathrm{F}$ & $\mathrm{HM}$ & 24 & 14 & 1 & $12-72$ & $\begin{array}{l}\text { Sleep deprivation, } \\
\text { physical exertion }\end{array}$ & - & - \\
\hline$\| 1-4$ & $\mathrm{~F}$ & $\mathrm{HM}$ & 31 & 16 & 3 & $0,5-48$ & Menstruations & - & - \\
\hline II-5 & M & $\mathrm{HM}$ & 35 & 15 & 2 & $0,5-48$ & - & thrombophilia & - \\
\hline II-6 & $\mathrm{F}$ & $\mathrm{HM}$ & 22 & 12 & 3 & $1-72$ & $\begin{array}{l}\text { Alcohol intake, } \\
\text { menstruations }\end{array}$ & - & - \\
\hline
\end{tabular}

Abbreviations: IHS criteria, International Headache Society criteria; HM, hemiplegic migraine; ETTH episodic tension type headache; $M O$ migraine without aura; $D M$ 2 diabetes mellitus type 2; $A H$ arterial hypertension; COPD Chronic Obstructive Pulmonary Disease

and impaired consciousness of a 2-day duration. His past medical history was remarkable for type 2 diabetes, hypertension and Chronic Obstructive Pulmonary Disease (COPD). The patient has been suffering from migraine since the age of 6 years, with a mean frequency of 1 episode per month. Some of his attacks were accompanied by hemiparesis, hemisensory loss, aphasia, confusion, nausea and vomiting, with the symptoms lasting for hours to days. His previous frequency of hemiplegic attacks was of three per year of variable severity. Neurologic examination in between attacks was normal.

At the time of our observation, the neurological examination showed right hemiparesis, right Babinski sign and asymmetric pupils (right $>$ left). Cerebrospinal fluid profile was normal. The EEG showed a marked amplitude asymmetry of the background activity consisting in diffuse depression in left hemispheric fields without epileptiform abnormalities (Fig. 2, panel A). Brain CT scan and CT Angiography excluded acute cerebrovascular events. A further brain CT scan performed after 5 days confirmed the absence of acute ischemic or hemorrhagic lesions. Brain MRI could not be performed due to the incompatibility of a metallic pelvic device. Single-Photon Emission Computed Tomography (SPECT) was normal. A complete cardiologic assessment was unremarkable. Lamotrigine up to $100 \mathrm{mg} /$ day and acetazolamide 500 $\mathrm{mg} /$ day were prescribed as a preventive treatment.

During hospitalization, the right hemiparesis and aphasia completely resolved. A further EEG performed a week later (Fig. 2, panel B) was normal, showing symmetric background activity. In the next days, the patient developed a cerebellar syndrome with generalized hypotonia, gait ataxia and bilateral dysmetria. Moreover, during the hospitalization he had episodes of psychomotor agitation with visual hallucinations which improved with quetiapine. The patient was discharged and attended a neurorehabilitation program. He did not experience any further episodes of migraine, whereas cerebellar deficits remained stable even at a 18-month follow-up.

A further brain CT scan performed after 5 months did not show significant cerebellar atrophy.

\section{Family history}

The family history was remarkable for headache, with several cases of hemiplegic migraine.

Patient I-1 (Fig. 1, I-1) since the age of 25 years had suffered from recurrent attacks of migraine without aura (MO). She reported a single hemiplegic episode at the age of 30 years.

Patient I-2 (Fig. 1, I-2) has been having attacks of migraine with typical aura and experienced several hemiplegic attacks lasting up to days.

Patient I-3 (Fig. 1, I-3) has been suffering from migraine with aura and hemiplegic attacks since her early childhood. Since the age of 30, she has been free from attacks with motor aura.

Patient I-4 (Fig. 1, I-4) had frequent attacks of HM followed by drowsiness since the age of 12 . He had 10 severe long-lasting attacks which required hospitalization.

Patient I-6 (Fig. 1, I-6) has been having hemiplegic migraine since the age of 5 . He had multiple episodes of migraine associated with hemiparesis, sensory deficits, 


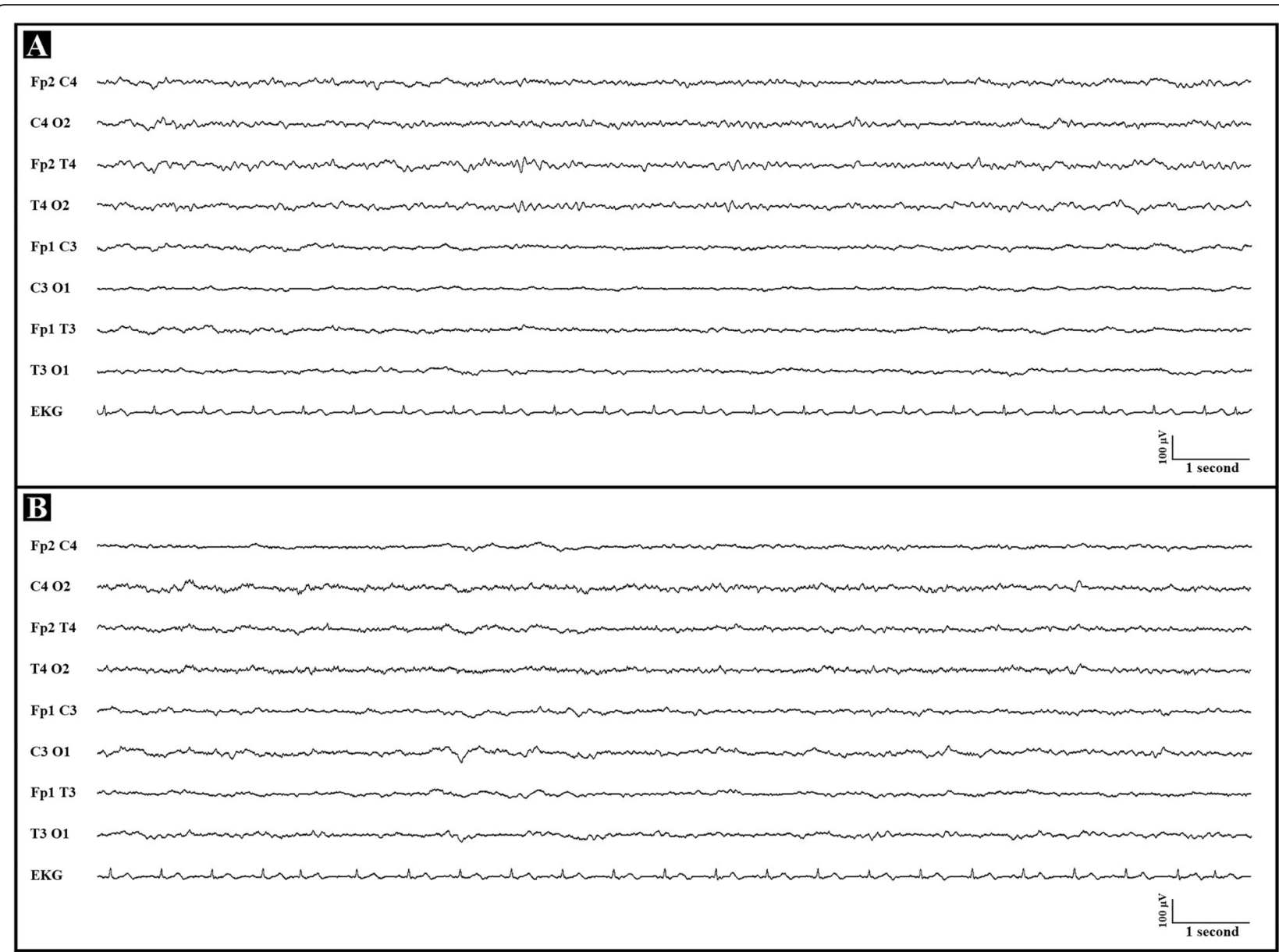

Fig. 2 Electroencephalogram findings. Panel A: fifteen seconds of ictal EEG: clear amplitude asymmetry of background activity consisting in diffuse depression in left hemispheric fields without epileptiform abnormalities. Panel $\mathbf{B}$ : fifteen seconds of normal interictal EEG

aphasia, diminished consciousness, fever and psychiatric symptoms with formed hallucinations, lasting up to 7 days.

Patient II-1 (Fig. 1, II-1) never suffered from hemiplegic attacks, but he was diagnosed with episodic tensiontype headache (ETTH). Patients II-3, II-4, II-5 and II-6 (Fig. 1, II-3, II-4, II-5 and II-6) had classic HM and patient II-2 was diagnosed with MO.

The index patient's father, not available for genetic analysis, had transient episodes of limb weakness followed by headache in his young adulthood.

\section{Results}

Analysis of CACNA1A revealed Thr501Met mutation in 12 of the 15 subjects screened, which was compatible with the diagnosis of FHM1. The 12 cases were 7 women (58.33\%) and 5 men (41.67\%). Mean age of onset was $14.4 \pm 5.2$ (range 6-24) and the mean age at examination was $50.4 \pm 21.3$ (range $22-76$ ).
Clinical characteristics and current prophylactic treatment of the 12 cases carrying CACNA1A mutation are summarized in Table 1.

Attacks of hemiplegic migraine that fulfilled the criteria of the ICHD-3 [1] were reported by 10 of the 12 subjects $(83.33 \%)$. The mean monthly migraine days in patients with $\mathrm{HM}$ was $2 \pm 1$.

All subjects affected by HM also reported attacks of migraine with non-hemiplegic aura and MO. One subject carrying p.Thr501Met mutation (8.33\%) was diagnosed with MO and one subject (8.33\%) with ETTH. Emotional stress, menstruations and sleep deprivation were the most frequent triggering factors.

None of the subjects, except for the index patient (Fig. 1, I-5), had ever experienced cerebellar symptoms.

A brain MRI scan was performed in 9 patients carrying CACNA1A mutation showing no cerebellar atrophy. 


\section{Discussion}

We described a large family with CACNA1A-p.Thr501Met mutation whose prevalent clinical expression was hemiplegic migraine. The heterozygous missense variant p.Thr501Met was described previously in association with episodic ataxia [8] and in one patient with FHM associated to cerebellar symptoms [9]. This mutation changes a hydrophilic amino acid versus a hydrophobic one, probably altering the characteristic transmembrane conformation of the $\mathrm{P} / \mathrm{Q}$ type calcium channel subunit $[8,9]$. P/Q type calcium channels are expressed in the brain and particularly in cerebellar Purkinje and granule cells. Different FHM mutations induce profound Purkinje cell dysfunctions finally leading to neuronal loss and cerebellar atrophy [6]. FHM1 has a broad clinical spectrum and more than half of the families have cerebellar involvement [7].

The index patient had a previous history of recurrent long-lasting hemiplegic migraine attacks sometimes associated with reduced consciousness, fever and psychiatric symptoms. The EEG left hemispheric depression during the first acute phase of the attack represents the neurophysiological correlate of the reversible cortical inhibition. Furthermore, the patient developed a cerebellar syndrome with persistent functional impairment. Acetazolamide and lamotrigine were effective in preventing further attacks.

Both hemiplegia and cerebellar involvement find an adequate explanation with the disfunction of the $\mathrm{P} / \mathrm{Q}$ type calcium channels subunit. Instead, the psychiatric manifestations are more difficult to justify. Hallucinations are commonly reported as a FHM acute presentation associated with migraine attacks $[10,11]$. Another possible explanation for the index patient's symptoms could be the occurrence of delirium in an elderly hospitalized patient. However, the patient had no relevant predisposing risk factors for delirium, other than old age, nor did he experience alcohol withdrawal, use of psychotropic medications, sleep deprivation, infections [12]. Furthermore, the psychiatric manifestation are consistent with the involvement of ion channels in other neuropsychiatric disorders [13]. In this view, the complexity of the clinical manifestations of our index patient confirms the crucial role of calcium voltage-gated channel subunit alpha-1A in CNS function.

None of the 12 patients of our family had permanent motor, sensory, language, visual symptoms except for the index patient who developed persistent cerebellar deficits.

Furthermore, in our family there was a remarkable clinical heterogeneity which could be explained by the variable penetrance of the CACNA1A mutations being the asymptomatic or mildly symptomatic cases mostly from the second generation $[7,14]$.

\section{Conclusion}

To conclude, the CACNA1A-p.Thr501Met mutation is associated with distinct phenotypes, ranging from cerebellar to hemiplegic syndromes. Our data suggest that CACNA1A-p.Thr501Met mutation can occur prevalently as hemiplegic migraine. However, it is not clear why some CACNA1A mutations cause a prevalent hemiplegic pattern, others a prevalent ataxic phenotype and others a complex mixed pattern.

\section{Supplementary Information}

The online version contains supplementary material available at https://doi. org/10.1186/s10194-021-01297-5.

\section{Additional file 1.}

\section{Acknowledgements}

not applicable.

Disclosures of all authors

the authors report no disclosures relevant to the manuscript.

\section{Authors' contributions}

$M R, G P, E R, S S, C V$ and $P C$ designed the study. MR, CV, ER aided in interpreting the results and worked on the manuscript. MR wrote the manuscript with input from all authors. LT contributed to the design and implementation of the research. SS, CV and PC were involved in planning and supervised the work. All authors discussed the results and commented on the manuscript. The author(s) read and approved the final manuscript.

\section{Funding}

No targeted funding declared.

Availability of data and materials no statistical analysis was conducted.

\section{Declarations}

Ethics approval and consent to participate

the study was carried out in compliance with the Helsinki Declaration and with the guidelines of the Ethical Committee of our Institution. Informed consent was obtained from all the participants to the study.

\section{Consent for publication}

a written informed consent was obtained from all patients about storage and use of their DNA samples for both diagnostic and clinical research studies concerning their disease.

\section{Competing interests}

the authors declare that they have no competing interests related to this manuscript.

\section{Author details}

${ }^{1}$ Dipartimento Universitario di Neuroscienze, Università Cattolica del Sacro Cuore, Rome, Italy. 'Dipartimento di Scienze dell'invecchiamento, Neurologia, Neurologiche, Ortopediche e della Testa-Collo, Fondazione Policlinico Universitario Agostino Gemelli IRCCS, Rome, Italy. ${ }^{3}$ Dipartimento di Scienze dell'invecchiamento, Neurofisiopatologia, Neurologiche, Ortopediche e della Testa-Collo, Fondazione Policlinico Universitario Agostino Gemelli IRCCS, Largo Agostino Gemelli n 8 -, 00168 Rome, Italy. ${ }^{4}$ Dipartimento di Neuroscienze e Neuroriabilitazione, Unità di Malattie Neuromuscolari e Neurodegenerative, IRCCS Ospedale Pediatrico Bambino Gesù, Rome, Italy. 
Received: 17 June 2021 Accepted: 12 July 2021

Published online: 28 July 2021

\section{References}

1. Headache Classification Committee of the International Headache Society (IHS). The International Classification of Headache Disorders, 3rd edition (2018). Cephalalgia 38(1):1-211. https://doi.org/10.1177/0333102417738202

2. Ophoff RA, Terwindt GM, Vergouwe MN, van Eijk R, Oefner PJ, Hoffman SM, Lamerdin JE, Mohrenweiser HW, Bulman DE, Ferrari M, Haan J, Lindhout D, van Ommen GJ, Hofker MH, Ferrari MD, Frants RR (1996) Familial hemiplegic migraine and episodic ataxia type-2 are caused by mutations in the Ca2+ channel gene CACNL1A4. Cell 87(3):543-552. https://doi.org/10.1016/s00928674(00)81373-2

3. Alonso I, Barros J, Tuna A, Coelho J, Sequeiros J, Silveira I, Coutinho P (2003) Phenotypes of spinocerebellar ataxia type 6 and familial hemiplegic migraine caused by a unique CACNA1A missense mutation in patients from a large family. Arch Neurol 60(4):610-614. https://doi.org/10.1001/archneur. 60.4 .610

4. Riant F, Roze E, Barbance C, Méneret A, Guyant-Maréchal L, Lucas C, Sabouraud P, Trébuchon A, Depienne C, Tournier-Lasserve E (2012) PRRT2 mutations cause hemiplegic migraine. Neurology 79(21):2122-2124. https:// doi.org/10.1212/WNL.0b013e3182752cb8

5. Di Stefano V, Rispoli MG, Pellegrino N, Graziosi A, Rotondo E, Napoli C, Pietrobon D, Brighina F, Parisi P (2020) Diagnostic and therapeutic aspects of hemiplegic migraine. J Neurol Neurosurg Psychiatry 91(7):764-771. https://doi.org/10.1136/jnnp-2020-322850

6. Russell MB, Ducros A (2011) Sporadic and familial hemiplegic migraine: pathophysiological mechanisms, clinical characteristics, diagnosis, and management. Lancet Neurol 10(5):457-470. https://doi.org/10.1016/S14 74-4422(11)70048-5

7. Ducros A, Denier C, Joutel A, Cecillon M, Lescoat C, Vahedi K, Darcel F, Vicaut E, Bousser MG, Tournier-Lasserve E (2001) The clinical spectrum of familial hemiplegic migraine associated with mutations in a neuronal calcium channel. N Engl J Med 345(1):17-24. https://doi.org/10.1056/NEJM2 00107053450103

8. Mantuano E, Romano S, Veneziano L, Gellera C, Castellotti B, Caimi S, Testa D, Estienne M, Zorzi G, Bugiani M, Rajabally YA, Barcina MJ, Servidei S, Panico A, Frontali M, Mariotti C (2010) Identification of novel and recurrent CACNA1A gene mutations in fifteen patients with episodic ataxia type 2. J Neurol Sci 291(1-2):30-36. https://doi.org/10.1016/j.jns.2010.01.010

9. Carreno O, Corominas R, Serra SA, Sintas C, Fernandez-Castillo N, Vila-Pueyo M, Toma C, Gene GG, Pons R, Llaneza M, Sobrido MJ, Grinberg D, Valverde MA, Fernandez-Fernandez JM, Macaya A, Cormand B (2013) Screening of CACNA1A and ATP1A2 genes in hemiplegic migraine: clinical, genetic, and functional studies. Mol Genet Genomic Med 1(4):206-222. https://doi.org/1 $0.1002 / \mathrm{mgg} 3.24$

10. Barros J, Mendes A, Matos I, Pereira-Monteiro J (2012) Psychotic aura symptoms in familial hemiplegic migraine type 2 (ATP1A2). J Headache Pain 13(7):581-585. https://doi.org/10.1007/s10194-012-0462-5

11. Topakian R, Pischinger B, Stieglbauer K, Pichler R (2014) Rare clinical findings in a patient with sporadic hemiplegic migraine: FDG-PET provides diminished brain metabolism at 10-year follow-up. Cephalalgia 34(5):392396. https://doi.org/10.1177/0333102413513182

12. Inouye SK, Westendorp RGJ, Saczynski JS (2014) Delirium in elderly people. Lancet (London, England) 383(9920):911-922. https://doi.org/10.1016/S01406736(13)60688-1

13. Gargus JJ (2006) lon channel functional candidate genes in multigenic neuropsychiatric disease. Biol Psychiatry 60(2):177-185. https://doi.org/10.1 016/j.biopsych.2005.12.008

14. Thomsen LL, Kirchmann M, Bjornsson A, Stefansson H, Jensen RM, Fasquel AC, Petursson H, Stefansson M, Frigge ML, Kong A, Gulcher J, Stefansson K, Olesen J (2007) The genetic spectrum of a population-based sample of familial hemiplegic migraine. Brain 130(Pt 2):346-356. https://doi.org/10.1 093/brain/awl334

\section{Publisher's Note}

Springer Nature remains neutral with regard to jurisdictional claims in published maps and institutional affiliations.

Ready to submit your research? Choose BMC and benefit from:

- fast, convenient online submission

- thorough peer review by experienced researchers in your field

- rapid publication on acceptance

- support for research data, including large and complex data types

- gold Open Access which fosters wider collaboration and increased citations

- maximum visibility for your research: over $100 \mathrm{M}$ website views per year

At BMC, research is always in progress.

Learn more biomedcentral.com/submissions 